\title{
MiR-145 inhibits proliferation of primary colon adenocarcinoma cells via induction of apoptosis, cell cycle arrest and inhibition of cell migration
}

\author{
Yong Yang ${ }^{1}$, Peng $\mathrm{Li}^{2}$, Xu-feng Ding ${ }^{2}$, Xi Ming ${ }^{2}$, Xiu-tian Guo ${ }^{1 *}$ \\ ${ }^{1}$ Department of Anus \& Intestine, ${ }^{2}$ College of Clinical Medicine, Shanghai Hospital of Traditional Chinese Medicine, Shanghai \\ 200071, China \\ *For correspondence: Email: GastInellazalo@yahoo.com; Tel/Fax: 0086-021-56639828
}

Sent for review: 9 December 2017

Revised accepted: 22 July 2018

\begin{abstract}
Purpose: To investigate the role and potential of miR-145 as a therapeutic target for the treatment of primary colon adenocarcinoma in cell lines

Methods: The expression of miR145 was determined by quantitative real time-polymerase chain reaction (RT-PCR), while cell viability was determined by MTT assay. Apoptosis was assessed by 4',6diamidino-2-phenylindole (DAPI), acridine orange/ethidium bromide (AO/EB), and annexin V/PI double staining. Cell cycle analysis was performed by flow cytometry, while immunoblotting was used to determine protein expression.

Results: The expression of miR-145 was significantly enhanced in all the colon adenocarcinoma cell lines investigated. On the other hand, suppression of miR-145 expression led to significant decrease in cell viability, activation of apoptosis, G2/M cell cycle arrest, and inhibition of migration of colon adenocarcinoma cells.

Conclusion: These results indicate that miR-145 regulates the proliferation and metastasis of colon adenocarcinoma cells. Thus, it may be a prospective drug target for the treatment of this disease.
\end{abstract}

Keywords: MicroRNA, Apoptosis, Cell migration, Proliferation

\begin{abstract}
This is an Open Access article that uses a funding model which does not charge readers or their institutions for access and distributed under the terms of the Creative Commons Attribution License (http://creativecommons.org/licenses/by/4.0) and the Budapest Open Access Initiative (http://www.budapestopenaccessinitiative.org/read), which permit unrestricted use, distribution, and reproduction in any medium, provided the original work is properly credited.

Tropical Journal of Pharmaceutical Research is indexed by Science Citation Index (SciSearch), Scopus, International Pharmaceutical Abstract, Chemical Abstracts, Embase, Index Copernicus, EBSCO, African Index Medicus, JournalSeek, Journal Citation Reports/Science Edition, Directory of Open Access Journals (DOAJ), African Journal Online, Bioline International, Open-J-Gate and Pharmacy Abstracts
\end{abstract}

\section{INTRODUCTION}

Primary colon adenocarcinoma is one of the lethal cancers, and is responsible for significant level of mortality across the globe [1]. The current treatment for colon adenocarcinoma involves surgery and chemotherapy. However, the success rate of these treatments is low. Moreover, a number of adverse effects are associated with currently available drugs [2,3].
Therefore there is need to identify and study newer and more efficient drugs with minimum side effects, as well as novel therapeutic targets.

MicroRNAs are small molecules and they are not translated into proteins [4,5]. Diverse roles have been ascribed to microRNAs. For example, it is believed that the expressions of thousands of genes in humans are controlled by microRNAs. In addition, cell proliferation is regulated by microRNAs from several types of cells [6]. The 
miRNAs have also been implicated in the development and progression of some deadly diseases, including cancer [7]. Therefore, they are considered as potential therapeutic targets [8].

In the present study, the expressions of MiR-145 in four different colon adenocarcinoma cell lines were determined. In addition, the effect of miR145 on the proliferation, cell viability and migration of the human colon adenocarcinoma cells were investigated.

\section{EXPERIMENTAL}

\section{Chemicals, reagents and cell cultures}

All chemicals and reagents were procured from Sigma-Aldrich Co. (St. Louis, MO, USA), unless otherwise indicated. Four human primary colon adenocarcinoma cell lines (WiDr, SW48, LS123, LS180), and one normal colon cell line (CCD18Co) were obtained from Type Culture Collection of Chinese Academy of Sciences, Shanghai, China. The cells were grown in RPMI1640 medium and maintained at standard culturing conditions.

\section{RNA isolation, cDNA synthesis and analysis of expression}

The total RNA was extracted from the colon adenocarcinoma cells with RNeasy Kits (Qiagen), and Omniscript RT (Qiagen) was employed to reverse-transcribe the cDNA using 1 $\mu \mathrm{g}$ of the extracted RNA. The cDNA was then used as template for quantitative real-time PCR (qRT-PCR), with Taq PCR Master Mix Kit (Qiagen) in line with the guidelines of the instrument manufacturer.

\section{Inhibition of miR-145}

The inhibitor of human miR-145 (MiR145-In, 107 units $/ \mathrm{mL}$ ), and its non-specific miRNA lentivirus (MiR-C, 107 units $/ \mathrm{mL}$ ) were procured from GenePharma (Shanghai, China). The SW48 cells were then incubated with lentiviral particles and polybrene $(8 \mathrm{mg} / \mathrm{mL})$ for $48 \mathrm{~h}$. Thereafter, the cells were harvested, cultured in a fresh medium, and incubated further for $3-7$ days for stable transduction. The cells were then passaged and preserved in vitro for use in subsequent experimentation.

\section{Cell viability assay}

The cell viability of the lung cancer cells was assessed by MTT assay. The lung cancer cells were seeded in 96-well plates at a density of $2 \mathrm{x}$
$10^{5}$ cells/well. The cells were then incubated with MTT at $37{ }^{\circ} \mathrm{C}$ for $4 \mathrm{~h}$. Thereafter, absorbance was read at $570 \mathrm{~nm}$ in a microplate reader at different time intervals ( 24 and $48 \mathrm{~h}$ ) to determine the viability of the cells.

\section{Apoptotic assays}

Colon adenocarcinoma cells (SW48) were cultured in 6-well plates at a density of $1 \times 10^{6}$ cells per well, and incubated for $24 \mathrm{~h}$. This was immediately followed by DAPI staining. Then, the cell samples were examined and photographed with a fluorescence microscope. To determine populations of apoptotic SW48 cells, the cells were platted in 6-well plates and treated with Annexin V/FITC and PI for $20 \mathrm{~min}$. The percentage of apoptotic cells was determined by flow cytometry (BDBiosciences, San Jose, CA, USA).

\section{Cell cycle analysis}

The distribution of the SW48 cells in different phases of cell cycle was investigated by seeding approximately $1 \times 10^{5}$ cells in each well of a 6 -well plate. The cells were transfected with miR-145containing vector, or with empty vector, and kept at $37^{\circ} \mathrm{C}$ overnight to allow for adherence. Then, the distribution of the SW48 cells in various cell cycle phases was determined by flow cytometry.

\section{Wound healing assay}

The capacity of the SW48 cells to migrate was determined by wound healing assay. The cells were seeded at a density of $5 \times 10^{4}$ cells/well and cultured in 96-well plates. The plates were then incubated overnight at $37{ }^{\circ} \mathrm{C}$ to achieve adherence. A sterile pipette tip was then used to scratch the cell culture, and the cells were washed with phosphate-buffered saline to remove the detached cells. The SW48 cells were then photographed after 48 to assess their migration.

\section{Western blot analysis}

The SW 48 cells were lysed in ice-cold hypotonic buffer. Protein concentration was estimated in each cell extract, the protein samples were subjected to electrophoresis (SDS-PAGE). This was followed by transference to a nitrocellulose membrane and incubation with the primary antibody $(1: 1000)$ for $24 \mathrm{~h}$ at $4{ }^{\circ} \mathrm{C}$. Thereafter the membrane was incubated with $\mathrm{HRP}$-conjugated secondary antibody (1:1000) at $24^{\circ} \mathrm{C}$ for about 1 $h$, and the protein bands were visualised by enhanced chemi-luminescence. 


\section{Statistical analysis}

Each experiment was repeated three times and the results presented as mean $\pm S D$. One way ANOVA and Tukey's test were used for statistical analysis. Difference between the samples were considered statistically significant at $p<0.05$.

\section{RESULTS}

\section{Expression of miR-145 in colon adenocarcinoma cell lines}

The results revealed that the transcripts of miR145 were significantly upregulated in all the colon adenocarcinoma cell lines (WiDr, SW48, LS123, and LS180), when compared to the normal colon cell line (CCD-18Co) $(p<0.05$, Figure 1). The WiDr cell line exhibited the lowest expression of miR-145, while SW48 cell line showed the highest expression of miR-145. Thus, SW48 cell line was selected for further experimentation.

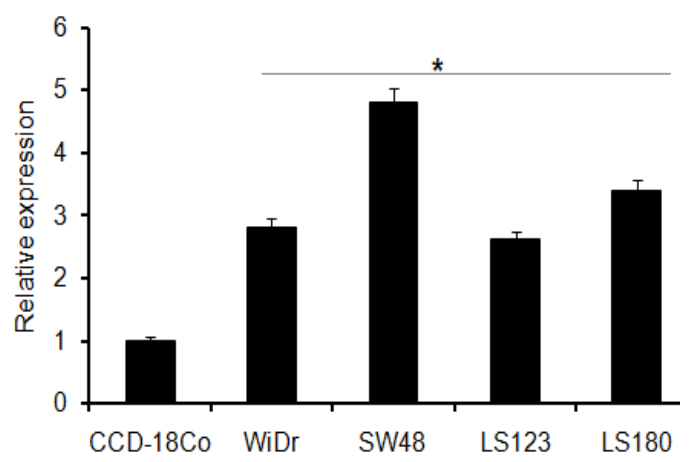

Figure 1: Expression of miR-145 in different primary colon adenocarcinoma cell lines (WiDr, SW48, LS123 and LS180) compared to miR-145 expression in normal colon cell line (CCD-18Co). Values are mean \pm $\left.\mathrm{SD} ;{ }^{*} p<0.05\right)$

\section{Downregulation of miR-145 promoted apoptosis}

The expression of miR-145 was suppressed in SW48 cells through lentiviral transfection, in order to find out its role in colon adenocarcinoma cell line SW48. The results revealed that cells in which miR-145 expression was inhibited had less cell viability than the control SW48 cells without miR-145 inhibition (Figure 2). These findings suggest that down-regulation of miR-145 in SW48 cells suppressed their viability. Results from DAPI, EB/OR and Annexin-V/PI staining revealed that the suppression of miR-145 in SW48 cells triggered apoptotic cell death (Figure 3). Thus, miR-145 suppression decreased cell viability via inducement of apoptosis.

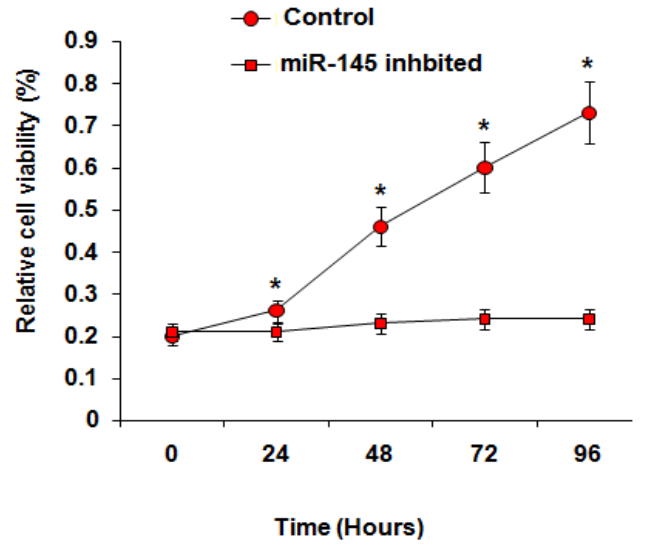

Figure 2: Effect of miR-145 inhibition of cell viability. The experiments were carried out in triplicates and expressed as mean $\pm \mathrm{SD}\left({ }^{*} p<0.05\right.$ vs control)
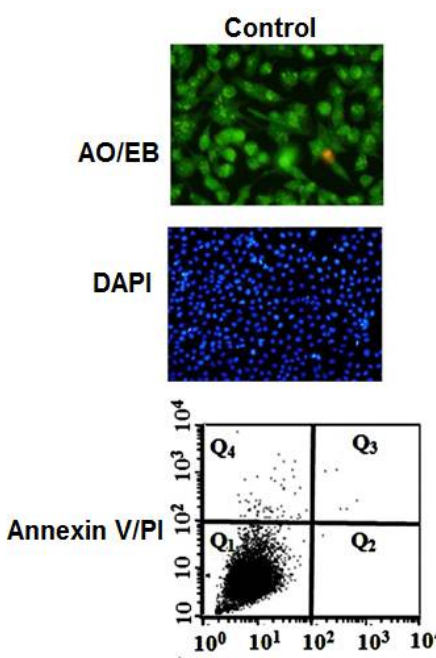
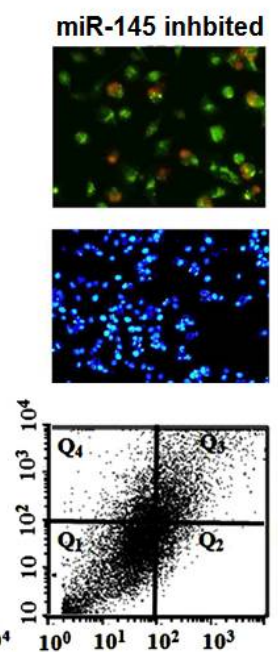

Figure 3: Inhibition of miR-145 promotes apotosis in SW48 colon adecarcinoma cells as indicated by AO/EB, DAPI and annexin V/PI staining. The experiments were carried out in triplicates

\section{Down-regulation of miR-145 caused G2/M cell cycle arrest}

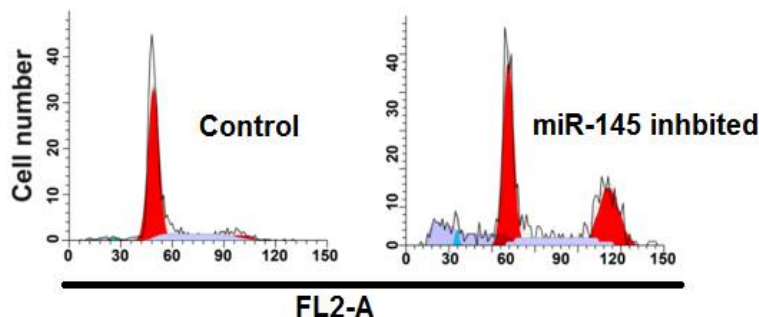

Figure 4: Inhibition of miR-145 triggers G2/M cell cycle arrest in SW8 colon adenocarcinoma cell lines. The experiments were carried out in triplicate

It was revealed that the cells treated with miR145 mimics accumulated in G2/M phase of the cell cycle, in contrast to the control SW48 cells (Figure 4). Thus miR-145 exerted antiproliferative effects on the SW48 colon 
adenocarcinoma cells partly through $\mathrm{G} 2 / \mathrm{M}$ cell arrest.

\section{Suppression of miRNA-145 inhibited cell invasion}

Results from wound healing assay revealed that suppression of miR-145 significantly decreased the cell migration capacity of SW48 cells after 20 h. Relative cell migration in the SW8 cells treated with mimics-NC was $34 \%$, while $17 \%$ migration was obtained in SW48 treated with miR-145 mimics (Figures 5A - 5B).

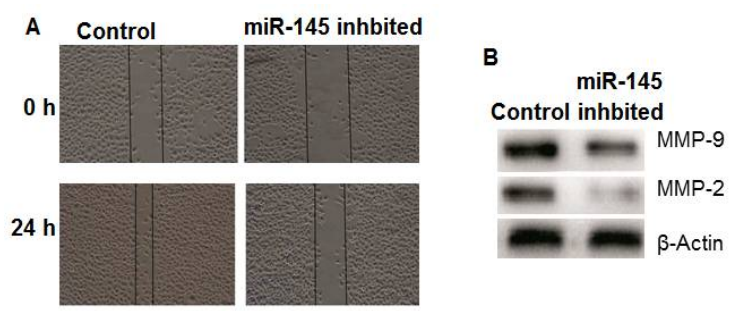

Figure 5: Effect of miR-145 on (A) Cell migration as determined by wound healing assay (B) Expression of MMP-9 and MMP-2 as determined by western blotting. The experiments were carried out in three biological replicates

\section{DISCUSSION}

Colon adenocarcinoma contributes to the high rate of cancer-related mortality world-wide $[9,10]$. The current treatments for colon adenocarcinoma have lots of adverse side effects and could be toxic to the patients. These shortcomings have necessitated interest in the screening and identification of novel and safer therapeutic targets [11]. In the last few decades, miRNAs have emerged as strong candidates with potential as prospective therapeutic targets for the treatment of cancers [12]. The expressions of a number of miRNAs are altered in cancerous tissues. In the present study, the expressions of miR-145 in colon adenocarcinoma and normal cell lines were investigated, and the results showed that the expression of miR-145 was significantly upregulated in all adenocarcinoma cell lines studied. These findings are in agreement with previous investigations which reported upregulation of the expression of miR-145 in breast and colorectal cancer cells [13,14].

The silencing of miR-145 expression with lentiviral transduction of miR-145 inhibitor triggered time-dependent decreases in cell viability of adenocarcinoma SW48 cells. In previous studies, it was also observed that suppression of mIR-145 inhibited the proliferation of several types of colon cancer cells.
Interestingly, the suppression of miR-145 expression induced apoptosis and G2/M cell cycle arrest in SW48 colon adenocarcinoma cells. It is has been reported that apoptosis and cell cycle arrest are two important mechanisms for assessing the growth and proliferation of cancer cells $[15,16]$. Thus, miR-145 can be considered an important target for anticancer drugs. Cell migration also plays an essential role in the metastasis of cancer cells [17]. In the present study, suppression of miR-145 expression also inhibited the migration of colon adenocarcinoma SW48 cells. This finding reinforces the potential of miR-145 as a therapeutic target.

\section{CONCLUSION}

The results of the present study indicate that the expression of miR-145 is upregulated in colon adenocarcinoma cells, while its suppression promotes apoptosis, triggers cell cycle arrest and inhibits cell migration. Therefore, miR-145 is most likely to be a potential therapeutic target for the treatment of colon adenocarcinoma.

\section{REFERENCES}

1. Hanif $R$, Qiao L, Shiff SJ, Rigas B. Curcumin, a natural plant phenolic food additive, inhibits cell proliferation and induces cell cycle changes in colon adenocarcinoma cell lines by a prostaglandin-independent pathway. $J$ LabClin Med1997; 130(6): 576-584.

2. Rosenberg SA, Spiess $P$, Lafreniere $R$. A new approach to the adoptive immunotherapy of cancer with tumorinfiltrating lymphocytes. Sci 1986; 233(4770): 13181321.

3. Hanif R, Qiao L, Shiff SJ, Rigas B. Curcumin, a natural plant phenolic food additive, inhibits cell proliferation and induces cell cycle changes in colon adenocarcinoma cell lines by a prostaglandin-independent pathway. J LabClin Med 1997; 130(6): 576-584.

4. Bartel DP. MicroRNAs: genomics, biogenesis, mechanism, and function. Cell2004;116(2):281-297.

5. Ambros $V$. The functions of animal microRNAs. Nature 2004; 431(7006): 350-355.

6. Bartel DP. MicroRNAs: target recognition and regulatory functions. Cell 2009; 136(2): 215-233.

7. Esquela-Kerscher A, Slack FJ. Oncomirs-microRNAs with a role in cancer. Nature Rev Can 2006; 6(4): 259269.

8. Schetter AJ, Leung SY, Sohn JJ, Zanetti KA, Bowman ED, Yanaihara N, Yuen ST, Chan TL, Kwong DL, Au $G K$, et al. MicroRNA expression profiles associated with prognosis and therapeutic outcome in colon adenocarcinoma. JAMA 2008; 299(4): 425-436. 
9. Jemal $A$, Siegel R, Ward E, Murray $T, X u J$, Smigal $C$, Thun MJ. Cancer statistics, 2006. CA: a cancer journal for clinicians. 2006; 56(2): 106-130.

10. O'Connell JB, Maggard MA, Ko CY. Colon cancer survival rates with the new American Joint Committee on Cancer sixth edition staging. J National Cancer Inst 2004; 96(19): 1420-1425.

11. Collins I, Workman P. New approaches to molecular cancer therapeutics. Nature ChemBiol 2006; 2(12): 689 700.

12. Garzon R, Calin GA, Croce CM. MicroRNAs in cancer. Annual review of medicine 2009; 60: 167-179.

13. Spizzo R, Nicoloso MS, Lupini L, Lu Y, Fogarty J, Rossi $S$, Zagatti B, Fabbri M, Veronese A, Liu X, et al. miR145 participates with TP53 in a death-promoting regulatory loop and targets estrogen receptor- $\alpha$ in human breast cancer cells. Cell Death Differentiat 2010; 17(2): 246-254.

14. Slaby O, Svoboda M, Fabian $P$, Smerdova $T$, Knoflickova $D$, Bednarikova $M$, Nenutil $R$, Vyzula $R$. Altered expression of miR-21, miR-31, miR-143 and miR-145 is related to clinicopathologic features of colorectal cancer. Oncol 2007; 72(5-6): 397-402.

15. Evan Gl, Vousden KH. Proliferation, cell cycle and apoptosis in cancer. Nature 2001; 411(6835): 342-348.

16. Fisher DE. Apoptosis in cancer therapy: crossing the threshold. Cell 1994; 78(4): 539-542.

17. Jones $D H$, Nakashima $T$, Sanchez $O H$, Kozieradzki I, Komarova SV, Sarosi I, Morony S, Rubin E, Sarao R, Hojilla CV, et al. Regulation of cancer cell migration and bone metastasis by RANKL. Nature 2006; 440(7084): 692-696. 